\title{
Considerações de implantação de bibliotecas públicas municipais no estado da Bahia
}

\author{
Jovenilda Freitas dos Santos
}

\begin{abstract}
Resumo: O artigo relata o processo de implantação de bibliotecas públicas municipais no Estado da Bahia, durante a gestão do governo do Presidente Lula. Ressalta a importância desse equipamento cultural e a relevância de políticas específicas para apoiá-las diretamente. $\mathrm{O}$ procedimento metodológico aplicado foi a pesquisa bibliográfica e documental, do tipo exploratória, realizada a partir de abordagem qualitativa, no sentido de buscar esclarecer práticas, colaborar e propor intervenções. Conclui que as políticas existentes para as bibliotecas públicas municipais são contraditórias, quando na verdade estão basicamente subordinadas à política de livros, cumprindo apenas papel de coadjuvante, resultando, por vezes, para o desconhecimento de suas primordiais funções.
\end{abstract}

Palavras-chave: Biblioteca Pública - Políticas Públicas. Sistema Estadual de Bibliotecas - Bahia.

\section{INTRODUÇÃO}

No Brasil, o discurso de zerar o número de municípios sem bibliotecas públicas não é recente. De acordo com Paiva (2008), a Revolução Industrial ocorrida na Inglaterra impulsionou o desenvolvimento comercial e populacional no Brasil, sobretudo na Era Vargas (1930-1945); contudo, a indústria do livro carecia de bibliotecas para se expandir. A solução encontrada pelo Estado Novo foi fundar e manter Biblioteca Pública Municipal (BPM) em cada município brasileiro onde não a possuía, a fim de aquecer e sustentar a produção editorial e diminuir o déficit de analfabetos para alavancar de vez o bom desenvolvimento que o país atravessava. Então, criou-se pelo Decreto-Lei ${ }^{\circ}$ 93, de 21 de dezembro de 1937, o Instituto Nacional do Livro (INL), órgão que assumiu a postura de administrar e executar políticas para as bibliotecas públicas municipais e estimular o mercado editorial.

A pesquisa decorreu da experiência, in loco, como agente do quadro de implantação de biblioteca pública no Estado da Bahia, ao vivenciar problemas acentuados por governos descontínuos, falta de fiscalização e de apoio técnico e 
operacional. Situação que permite refletir a importância de desenvolver políticas públicas que atendam significativamente a essa instituição humanitária, a qual visa desempenhar um elenco de funções imperativas para a sociedade, ao buscar cumprir com a missão de formar cidadãos por via do acesso irrestrito ao conhecimento. Mesmo que por vezes seja subutilizada por falta de políticas pertinentes para o seu fortalecimento perante a sociedade.

O panorama final revela a falta de políticas específicas para as bibliotecas, o que na prática a Colômbia vem demonstrando por meio de políticas públicas peculiares para bibliotecas, pensadas acima de legendas partidárias e/ou questões pessoais, que é possível elevar o grau de cultura e conhecimento de um povo e amenizar a violência tão presente em nosso país.

\section{METODOLOGIA}

Pesquisa bibliográfica do tipo exploratória, a partir da abordagem qualitativa por buscar esclarecer práticas e propor intervenções. O objetivo é relatar o processo de implantação de bibliotecas públicas municipais no Estado da Bahia, durante o governo do Presidente Lula, destacando a atuação do Sistema Estadual de Bibliotecas Públicas da Bahia (SEBP) no que concerne à implantação de bibliotecas públicas municipais, enfatizando critérios que os municípios deveriam obedecer para ser contemplados com o kit de biblioteca, além de discorrer como ocorreu na prática a instalação desse equipamento cultural nos municípios.

\section{ATUAÇÃO DO SISTEMA ESTADUAL DE BIBLIOTECAS PÚBLICAS DA BAHIA (SEBP) NA IMPLANTAÇÃO DE BIBLIOTECAS PÚBLICAS MUNICIPAIS}

A Fundação Pedro Calmon (FPC) foi criada no final da década de 1980 com a finalidade de promover a leitura e preservar a história e memória da Bahia. É o órgão que coordena o Sistema Estadual de Bibliotecas Públicas na Bahia, responsável por instalar bibliotecas nos municípios que nunca as possuíram ou encontravam-se 
desativadas. Também presta serviço de gerenciamento operacional, assistência técnica, capacitação dos recursos humanos para atuarem nas unidades instaladas, além de se articular com o Sistema Nacional de Bibliotecas Públicas (SNBP), para prestar informações atualizadas sobre as bibliotecas dos municípios baianos. Ou seja, atua como mediadora regional para apoiá-las.

O Presidente Lula, em cerimônia comemorativa dos 110 anos da Academia Brasileira de Letras, prometeu zerar o número de municípios brasileiros sem bibliotecas até 2008. Todavia o desejado não foi alcançado e acabou entrando como meta de número 32 no Plano Nacional de Cultura de 2011. Logo, somente no Estado da Bahia seria preciso instalar 134 bibliotecas do total de 417 municípios existentes atualmente.

Para beneficiar-se do Programa Livro Aberto: instalação de bibliotecas públicas, primeiro as cidades, representadas pelo Prefeito, celebravam contrato de comodato com a Fundação Biblioteca Nacional (FBN), acordando entre si nos termos da Lei $\mathrm{n}^{\circ}$ 10.406/2002, conforme artigos 579 a 584, estabelecendo critérios como:

a) aderir ao Sistema Estadual de Bibliotecas Públicas (SEBP), encaminhado relatório de suas atividades e cadastrando-se no SNBP;

b) empréstimo em regime de comodato dos bens móveis que irão compor o acervo da biblioteca pública de determinado município, visando a sua imediata disponibilização a todos os cidadãos no prazo máximo de 30 dias após o recebimento;

c) o município compromete-se também em dispor de espaço de fácil acesso para a comunidade, com no mínimo de $60 \mathrm{~m}^{2}$ de áreas física;

d) criar Biblioteca por lei Municipal;

e) incluir no orçamento anual do município, previsão de recursos para custear a manutenção e ampliação do acervo bibliotecário e do espaço físico;

f) estimular a criação de Associação de Amigos da Biblioteca ou entidade privada que tenha por objetivo o apoio à biblioteca;

g) disponibilizar um ramal ou uma linha telefônica para a administração da Biblioteca; 
h) promover ações de caráter cultural que estimulem o comparecimento de pessoas à Biblioteca;

i) envidar esforços para que a Biblioteca disponha do profissional bibliotecário. (FUNDAÇÃO BIBLIOTECA NACIONAL, 2007).

O contrato tinha vigência de três anos, podendo ser renovado por igual período, caso fosse do interesse das partes signatárias. Decorrido o prazo inicial, atendidos os objetivos do Programa, mediante comprovação fundamental, os bens poderiam ser incorporados ao patrimônio do comodatário como "doação da FBN."

A inobservância das cláusulas e condições firmadas permitia à FBN exigir a devolução dos bens entregues, ou a verba financeira correspondente dos mesmos, independente de notificação judicial ou extrajudicial.

\section{A PRÁtica de IMPLANTAÇÃo DE BIBLIOTECAS NO ESTADO DA BAHIA}

Durante o período de implantação de bibliotecas na Bahia, o primeiro passo do Sistema Estadual foi consultar em seus arquivos dados da real situação dos municípios, sobretudo em relação à existência ou não de bibliotecas. Nesse bojo, levantou que 134 municípios não possuíam ou nunca possuíram bibliotecas públicas municipais. Então, enviou-se formulários para os governantes dessas regiões, solicitando a documentação necessária para celebrar convênio e garantir o beneficiamento dessas regiões com o kit de implantação de biblioteca, composto por acervo estimado em dois mil livros, mobiliários, computador e outros itens.

Atualizar os dados dos relatórios de biblioteca foi um verdadeiro desafio, pois grande parte estava incompleto, desatualizado ou simplesmente não existia. Fruto bastante derivado de mudança de governo, o qual costuma provocar troca de gestão, e geralmente descontinuidade de políticas públicas preestabelecidas. Desse modo, favorece a prática de desapropriação de bibliotecas e mudança de local. Manter atualizado o cadastro de todas as bibliotecas brasileiras é uma das normas do Decreto 520 de 13 de maio de 1992, o qual reinstitui o Sistema Nacional de Bibliotecas Públicas 
(SNBP). Contudo, alguns municípios baianos foram contemplados duplamente, enquanto outros que não possuíam bibliotecas não foram atendidos de imediato, às vezes bibliotecas existiam apenas no papel. Logo, percebia o descumprimento dessa normativa, evidenciando a desarticulação do Sistema estadual com o nacional, quando deixava de coletar e repassar informações atualizadas para o bom funcionamento das ações.

Dentre os critérios propostos para o recebimento do acervo e demais equipamentos, o Prefeito do município comprometia-se em manter o espaço físico adequado, via declaração informando dispor de local adequado; planta baixa do imóvel, ou o croqui; escritura do imóvel ou do contrato de locação e fotografias externas e internas. Visto habitualmente os municípios apresentarem pendências como certidão negativa de débitos junto ao INSS; certidão de regularidade junto ao FGTS e certidão de regularidade com a Fazenda Estadual, não mais se solicitou tais documentos por ser um entrave ao processo de implantação.

Ao apresentar a documentação exigida pelo Programa, estando o município regularmente habilitado para receber o kit, e os colaboradores aptos para ajudar no processo de implantação, elaborava-se um roteiro de viagem para as equipes que iram organizar o acervo e capacitar os recursos humanos que atuariam na biblioteca. A equipe técnica era composta por um quadro fixo de 1 bibliotecário coordenador e 1 técnico de biblioteca. Antes, chegou a ser integrada por 6 profissionais entre bibliotecários e técnicos, porém muitos deles se aposentaram, e como o Estado não realiza concurso para contratação efetiva de bibliotecário desde 1995, tal situação agravava-se. A solução foi solicitar junto à rede de bibliotecas públicas estaduais da cidade de Salvador, bibliotecários e auxiliares para colaborar no processo de implantação.

No início, aqueles que atuariam nas bibliotecas instaladas recebiam treinamento na biblioteca pública do Estado, localizada em Salvador. Ocorre que, por vezes, alguns municípios não enviavam representantes, comprometendo ainda mais o funcionamento das unidades. Procurando evitar o que Milanesi (1997, p. 246) já disseminava: “De um modo geral, como regra, não há nenhuma forma de organização desses acervos, além de 
uma grosseira separação por assunto nas estantes”, optou-se em capacitá-los no próprio município, durante a execução dos trabalhos, e em poucos casos elegia-se uma cidade polo para monitorar o curso de auxiliar de biblioteca. $\mathrm{O}$ critério de escolha da cidade recaia sob a mais próxima de todos os eleitos para participar do curso, e que também seria contemplada com o kit de implantação. Essa seleção já era praticada em diversos estados brasileiros, a exemplo do Rio Grande do Sul, como bem informa Rosa (1982, p. 147-148):

\begin{abstract}
Para realização do treinamento, é selecionado para sediar o curso, um município pólo-cultural, situado em área ainda não atingida pelos treinamentos. Os municípios vizinhos são convidados a enviarem bolsistas. O treinamento reúne no mínimo 15 pessoas, têm a duração de uma semana e seus instrutores são de preferência, bibliotecários que atuam no Sistema.
\end{abstract}

Nos anos seguintes esses funcionários eram convidados a participarem de encontros para discutir questões relativas às suas unidades de trabalho, ensejando socializar e reciclar conhecimentos para melhorar os serviços prestados, corrigir falhas, ou até mesmo abandonar práticas obsoletas.

O curso intensivo de auxiliar de biblioteca era ministrado de modo prático, com ênfase na promoção de ações que divulgassem a biblioteca, o empréstimo domiciliar, a formação do acervo bibliográfico, leitura e ordenação das obras nas estantes, relatórios de controle sobre o uso dos serviços e frequência de usuários na biblioteca. Também dava-se uma atenção especial para com a memória do município, a fim de preservar a identidade cultural no contexto em que se situava. Então, buscava-se informações sobre a cultura local, suas raízes, influências, evolução e outras informações correlatas.

O processamento técnico do acervo, antes era preparado no próprio município, com a informatização passou a ser processado na biblioteca pública do Estado, a qual competia classificá-lo e catalogá-lo. A equipe, in loco, cabia colar as etiquetas com o 
número de chamada nos livros e tombá-los para ordená-los nas estantes. Foi de grande contribuição tecnológica a utilização do sistema Biblivre ${ }^{1}$, por acelerar o processo de implantação de bibliotecas, ao reduzir de duas para uma semana o período para implantar uma.

Chegando à cidade designada, a equipe de implantação se apresentava ao Prefeito ou secretário responsável pela pasta da biblioteca, munidos de carta de apresentação, assinada e datada pelo então Presidente da FPC. Em seguida, a equipe era conduzida para o local onde instalaria a biblioteca para consecução das tarefas operacionais. Embora os responsáveis pela biblioteca fossem pré-avisados quanto à necessidade de providenciar voluntários para ajudar nas tarefas, era comum os dirigentes disponibilizarem pessoas analfabetas ou com baixo nível escolar, dificultando o trabalho.

Outra triste surpresa ao chegar a alguns municípios, referia a não haver como implantar a biblioteca por não existir o espaço físico. O jeito era classificar e empacotar todo o acervo, na esperança do Prefeito cumprir, o mais breve possível, com a sua parte pré-firmada. Também compartilho de uma estranha vivência em campo, quando da visita para instalar uma biblioteca num determinado município, o secretário de cultura afirmou não desejar a biblioteca porque não traduziria benefícios para a população local. O cenário refletiu a falta de visão de alguns governantes ao dificultar o acesso ao conhecimento para sua comunidade. Se não existe preocupação em receber uma biblioteca ou dispor de espaço, supõe-se que outras obrigações como disponibilizar orçamento público anual para manter as ações básicas desenvolvidas nas bibliotecas não seriam também cumpridos.

As chamadas elites raramente procuram compreender $o$ significado do conhecimento para o desenvolvimento harmônico da sociedade, como se a perpetuação da ignorância fosse a sua própria sobrevivência. Isso, talvez, explique a marginalização das bibliotecas e outros serviços culturais ou a sua

\footnotetext{
${ }^{1}$ Sistema gratuito desenvolvido em software livre para gerenciar bibliotecas e que vem sendo utilizado pelas bibliotecas públicas implantadas recentemente.
} 
transformação em meros atrativos decorativos (MILANESI, 1997, p. 128).

A biblioteca pública é uma via de acesso ao conhecimento, cultura e lazer. Contudo, a maioria desses ambientes foram criados sem possuir sede própria, ou ocuparam diversos locais, e apenas alguns espaços foram construídos com assessoramento de bibliotecários (SUAIDEN, 1980). A afirmação comunga com o observado durante o processo de implantação, quando por vezes os governantes planejam o espaço e layout fora dos padrões do ambiente biblioteca, e também disponibilizam plantas e fotografias de um determinado espaço e, ao chegar à cidade, a equipe se deparava com outro espaço físico totalmente diferente do apresentado anteriormente. Complementando, era comum implantar bibliotecas ao meio das batucadas de martelo e ao cheiro de tinta fresca, devido ao espaço não ter ficado pronto a tempo, sendo prudentes algumas intervenções, a exemplo, construção ou remanejamento de paredes, colocação de forro, rede elétrica e outros problemas do gênero.

Caberia parceria contínua do profissional bibliotecário com o arquiteto para discutir quanto à divisão do espaço, visando o fim do replanejamento no ato da implantação, bem como harmonia entre as três esferas do governo (federal, estadual e municipal), para diminuir o ruído na comunicação e se articularem melhor, pois houve cidades que receberam o kit de implantação e não tinham nem conhecimento do que se tratava. Nesse sentindo, muitos governantes sentiam-se desobrigados de providenciar um espaço adequado, além de alegar falta de recurso financeiro. Mas, como a meta era colocar todas as cidades brasileiras no mapa daquelas que possuíam pelo menos uma biblioteca pública municipal até 2010, ignorava-se os critérios antes propostos. Na concepção de Almeida, Bastos e Romão (2008, p. 231): "Essas políticas assistencialistas pouco contribuíram para a formação de leitores e também não criaram verdadeiras bibliotecas, já que muitas obras sumiram como fumaça no ar."

Apesar de quase sempre bem localizadas, as bibliotecas eram desprovidas de boa infraestrutura. A Fundação Biblioteca Nacional (1995) orientava que elas deveriam 
prever acesso para portadores de deficiência física, áreas separadas para o acervo, para os serviços internos, para o ambiente de leitura e para as atividades culturais e de lazer, buscando evitar que uma atividade interfira na que ocorre em outro setor. Logo, o tamanho mínimo de $60 \mathrm{~m}^{2}$ e depois de $80 \mathrm{~m}^{2}$ de área física, sugerido pela Biblioteca Nacional, seria insuficiente. Segundo Milanesi (1997), tal determinação dá margem para que governantes, pouco interessados, disponibilizem espaços inadequados para acomodar o acervo e equipamentos da biblioteca. Para o autor: "Um município de 30. 000 mil habitantes deverá ter, minimamente, uma área de $300 \mathrm{~m}^{2}$ para as várias atividades culturais. Abaixo disso, será impossível abrigar o que se supõe que uma área destinada à Cultura deva ter" (MILANESI, 1997, p. 241).

Dentre o pessoal contratado para atuar na biblioteca, com base no perfil de cada um, a equipe técnica sempre opinava em qual setor o funcionário deveria atuar, e quem seria o mais preparado para ser o responsável geral. Todavia os governantes davam preferência a parentes ou cabos eleitorais. Alguns, não aparentados, confidenciavam que mesmo capacitados, logo após a partida da equipe, o quadro de pessoal corria sério risco de ser desfeito, e eles seriam os primeiros a serem demitidos. O desabafo de fato se consumava, bastava comparar a quantidade total de funcionários declarados no primeiro formulário bienal de atualização dessas bibliotecas com o subsequente, ou por via de contato deles com o Sistema estadual, para denunciar que estavam trabalhando sozinhos na unidade.

Quanto à contratação de bibliotecário nos municípios, das poucas vezes que se realizavam concursos públicos ofereciam-se valores irrisórios e confundia as atividades de auxiliar de biblioteca com as atribuições do bibliotecário, levando a pressupor o total desconhecimento referente às atividades desempenadas pelo bibliotecário. O resultado vai de encontro com a afirmativa de Milanesi (1997), quando já preconizava a respeito de bibliotecas geralmente dirigidas por profissionais não bibliotecários e bibliotecários desmotivados e sem a qualificação para desempenhar as tarefas de uma unidade atuante na comunidade. 
Do mesmo modo, para que um novo projeto, como o de bibliotecas municipais, tenha êxito, a primeira exigência é selecionar e nomear um bibliotecário bem capacitado, empreendedor e entusiasta, para ser o organizador da biblioteca municipal. Nenhum governador municipal deve cometer erro crasso de iniciar esse projeto sem atender a este pré-requisito básico. Se o cometer, estará somente tentando provar que o projeto não dará certo (RANGANATHAN, 2009, p. 75).

O Manifesto da Unesco também aconselha que a biblioteca deve possuir bibliotecário intermediando o acesso entre os utilizadores e os recursos disponíveis, sendo a sua formação profissional contínua, indispensável para assegurar serviços adequados, bom funcionamento e gestão atuante (INTERNATIONAL..., 1994).

Bibliotecas municipais atuando sem a presença do bibliotecário parece algo comum. A então gerente da Biblioteca Pública do Estado de Pernambuco, em entrevista a Cunha Júnior e Correia (2007), garantiu que em todo o Estado Pernambucano, dos 185 municípios, apenas 7 deles tinham bibliotecários coordenando bibliotecas públicas. Apesar do exposto, cabe destacar, casos em que foi possível presenciar profissionais que mesmo sem o diploma de bibliotecário exerciam com grande dedicação e zelo suas atividades na biblioteca.

A aquisição do kit de implantação foi em regime de comodato, entretanto não se efetivou política para fiscalizá-lo, nem punição para os transgressores. Assim, acervo e equipamentos ficavam mais suscetíveis ao sucateamento, e o município não se responsabilizou. Visando coibir atitudes desse teor, a equipe técnica costumava alertar os responsáveis para a existência da Lei $\mathrm{n}^{\circ}$ 9.605, de 12 de fevereiro de 1998, a qual dispõe sobre sanções penais e administrativas derivadas de condutas lesivas ao meio ambiente, incluindo dentre outras informações em seu Art. 62 da seção IV, que destruir inutilizar ou deteriorar equipamentos culturais como biblioteca, o infrator poderá por lei, ato administrativo ou decisão judicial, cumprir pena de reclusão de um a três anos e 
multa. Porém, essa lei nunca foi aplicada na prática durante todo o processo de implantação supracitado.

Ao regressar para sede de origem, o bibliotecário coordenador da implantação trazia na bagagem imagens e histórias de uma Bahia plural em seus mais variados aspectos, como o cultural, econômico, social e ambiental. Também trazia para ser anexado às pastas dos municípios o primeiro formulário bienal de atualização da biblioteca pública municipal e deixava os formulários estatísticos de frequência e uso dos serviços oferecidos pelas bibliotecas. Esses deveriam ser enviados para o Sistema Estadual a cada três meses. O método servia como um dos critérios para controlar e avaliar o desempenho das bibliotecas instaladas, isto é, julgar sua eficiência e utilidade, uma vez que a análise possibilitava avaliar objetivos estabelecidos, detectar eventuais desvios e efetuar correções necessárias. "É um instrumento essencial para a avaliação de desempenho, servindo também, para justificar pedidos de aumento de funcionários, de verbas para as atividades, etc.” (BIBLIOTECA NACIONAL, 2000, p. 42).

Dito isso, é importante que os relatórios contemplassem informações confiáveis, a fim de fornecer subsídios para implantar políticas pertinentes que atendessem à realidade de cada circunstância e ambiência investigada. Segundo informa o anuário estatístico das Bibliotecas Públicas do Estado da Bahia, publicado no final de 2010, 42 municípios baianos possuíam o profissional bibliotecário atuando nessas bibliotecas, e 23 deles possuíam pós-graduação. No entanto, quando consultados por e-mail ou telefone, constatou-se que apenas 17 desses municípios possuíam de fato o profissional bibliotecário (BAHIA, 2010). A oscilação de informação pode ser atribuída à questão de o bibliotecário mudar de emprego, por causa do baixo salário recebido; também muitos auxiliares se julgavam bibliotecários, por não saberem distinguir a diferença entre auxiliar e bibliotecário; e por fim, a informação do anuário pode reiterar o que a literatura preconiza a respeito dos dados coletados como meros registros quantitativo, impossíveis de serem analisados para produzir informações significativas.

A falta de dados estatísticos confiáveis para o planejamento bibliotecário é um problema que nunca foi resolvido satisfatoriamente, e até os dados fornecidos pelo Instituto Brasileiro de Geografia e Estatística (IBGE) eram insipientes para o processo, 
visto fornecer vários exemplos de problemas de definição, de agregação de dados e de interrupção de coletas (OLIVEIRA, 1994). Sem uma política para apoiar a biblioteca como uma unidade de informação significativa para a sociedade, "[...] o inestimável investimento é inútil, embora forneça números impressionantes para relatórios de final de gestão.” (PAIVA, 2008, p. 113).

Por fim, perseguindo a busca para cumprir a meta do governo federal de zerar o número de cidades brasileiras sem biblioteca, até o ano de 2010, o SEBP deu por implantadas entre 2007 a 2010, 143 bibliotecas públicas municipais, e capacitados 533 pessoas (BAHIA, 2010). Com ressalva para o município de Paripiranga, o qual embora tenha recebido todo o acervo, o então Prefeito não havia permitido a instalação da biblioteca, alegando não ter condições de recebê-la por não dispor de espaço adequado. A distinção entre os 134 municípios levantados sem bibliotecas, e os 143 implantados, justifica dado o fato dos municípios que já possuíam bibliotecas, também receberam o kit de implantação, equivocadamente.

Embora justificativa de falta de local para instalar biblioteca não devesse ser tolerada, ainda assim, era menos nefasto não implantá-las onde nem sequer existe o espaço para abrigá-la, do que informar que foi executado o serviço, sobretudo, para cumprir meta de governo de qualquer maneira. Visando coibir a prática de bibliotecas sendo fechadas e seu acervo sucateado, Juca Ferreira, quando Ministro da Cultura, instituiu uma portaria suspendendo o repasse de recursos para prefeituras que não tivessem pelo menos uma biblioteca pública municipal em funcionamento; afirmava ainda que, apesar desse instrumento não possuir caráter punitivo, ele almejava contemplar quem atuava adequadamente.

Bibliotecas com características das que foram implantadas nos municípios brasileiros, parece estar com os dias contados na Alemanha. Conforme informa Medeiros (2010, p. 21):

Klaus Ceynowa, diretor da Biblioteca Pública de Stuttgart, em uma apresentação na Fundação Biblioteca Nacional em 2010, previu o fim de certas bibliotecas físicas até o final de 2020, na Alemanha. As bibliotecas sobreviventes serão espaços 
patrimoniais e/ou espaços de encontro e troca de informação, cultura e lazer.

Para a colombiana, bibliotecária especialista em políticas públicas de apoio à leitura e à escrita Castrillón (2011, p. 22), “[...] são as bibliotecas os meios para a democratização do acesso, desde que nelas se produzam, também, importantes transformações." Então, a Colômbia, país em desenvolvimento como o Brasil, marcado pelo narcotráfico e violência, na prática vem demonstrando a importância das bibliotecas como instrumento social para a sociedade. Esse país tornou-se referência mundial e ganhou reconhecimento da Unesco, por investir em bibliotecas via agenda política e cultural que mudou a sua imagem, ao elevar o nível educacional do seu povo, além de diminuir os índice de violência em áreas consideradas violentas. Trata-se das Bibliotecas-Parque $^{2}$; nelas, além de livros, encontra-se cinema, cafeteria, salas destinadas a reuniões das comunidades, filmoteca, teatro, acervo digital de música, acesso gratuito à internet, sala de leitura para portadores de deficiências visuais e outros. Desse modo, tomando por referência as cidades colombianas de Medellín e Bogotá, já foram implantadas aqui no Brasil, em São Paulo, a Biblioteca de São Paulo (BSP), construída na área onde funcionou a Casa de Detenção do Carandiru. No centro do Rio de Janeiro, recentemente inaugurou a Biblioteca-Parque Estadual, responsável por coordenar todo o sistema estadual de bibliotecas, tornando-se a matriz da rede de Bibliotecas-parque implantadas nesse Estado, a ela já se integram as Bibliotecas-Parque das unidades da Rocinha, Niterói e Manguinhos (BRITO, 2014).

Acessibilidade é um ponto alto dessas unidades multifuncionais, por exemplo, a Biblioteca de São Paulo,

[...] conta com mesas reguláveis, que se adaptam a qualquer tamanho de cadeira de rodas, folheadores automáticos de páginas para aqueles que perderam os movimentos das mãos, e também computadores adaptados. Usuários cegos terão ainda mil títulos de "audiobooks" e um equipamento que,

\footnotetext{
${ }^{2}$ Conceito que integra ao ar livre bibliotecas e parque.
} 
automaticamente, é capaz de transpor obras literárias convencionais para faixas de áudio ou placas em braile (COMUNIDADE BIBLIOTECA VIVA, 2010, p. 1).

Materializado na política de ação cultural do governo, e sob o ponto de vista dos seus dirigentes, vale ressaltar que esse modelo de biblioteca lembra a experiência já experimentada antes no Brasil, em final dos anos 1960, quando se pensou a biblioteca num modelo personificado em núcleos de unidades culturais, dotados de sala Braille, museu da palavra, laboratório de microfilmagem, arquivo histórico, discoteca, biblioteca itinerante e infantil. Contudo, o custo inviabilizou a realização da proposta, e meramente uma unidade entrou em atividade na cidade de Natal no Rio Grande do Norte, mas foi desativada tão logo houve mudou da direção do Instituto Nacional do Livro (PAIVA, 2008).

Democratizar a cultura e a leitura parece ser conquista mais associada a diminuição das desigualdades e não ao passo em que os níveis de desenvolvimento melhorem. Castrillón (2011) rela que a desigualdade social ainda é o grande mal que afeta a Colômbia, embora os seus índices de desenvolvimento tenham aumentado.

\section{CONSIDERAÇÕES FINAIS}

No Estado da Bahia, embora as bibliotecas públicas municipais implantadas pelo programa do governo não se constituam em um modelo referencial, tornando-se passíveis de descarte ao primeiro momento de crise, elas estão presente na comunidade, promovendo dentro de suas limitações, empréstimos e atividades culturais, visando o desenvolvimento do hábito de leitura, lazer e cultura. Quanto mais próximas estiverem do seu público, maior chance terá de atendê-lo e de se fazer ser ouvida. Para tanto, é preciso dar a conhecer ao poder público e a sociedade civil a verdadeira missão da biblioteca pública, para que venha a ser mais bem entendida e seus objetivos cumpridos.

A Colômbia vem dando exemplo de que país em crescimento também é capaz de transformar a vida pessoal e coletiva do seu povo, por via de políticas públicas 
efetivas e exclusivas para bibliotecas. Logo, o crescimento de uma pátria não está restritamente condicionado ao grau de instrução do seu povo, mas pode ser alcançado quando se faz política pública pensando no bem comum, e em combater a desigualdade, acima de legenda partidária.

Implantar bibliotecas não significa o fim de uma tarefa, mas o início de uma batalha travada diariamente para conseguir cumprir com maestria seus objetivos. Sabemos que não será apenas a sua instalação o remédio que sanará os males sociais; esse papel compete primeiramente à família, à escola, e em seguida caberia a instituições como bibliotecas e arquivos dar-lhe suporte por meio de ações culturais, educacionais e de lazer, ao orientar usuários com informação e serviços para que eles sejam capazes de encontrar soluções para seus próprios problemas, de modo cada vez mais autônomo, num espaço dinâmico e atrativo.

Instalação de bibliotecas foi e será tarefa complexa; infinitos e imprevisíveis continuam sendo seus desdobramentos. Como já dizia Milanesi (1997, p. 219): “[Ela] nasce muito mais da organização e participação das pessoas do que da geração de programas estabelecidos de cima para baixo e à revelia dos destinatários."

Nessa contraditória arena, verificou-se que a biblioteca pública, mesmo com porta de acesso para o crescimento pessoal e coletivo, busca ainda por via de políticas públicas sua independência, pois o envio de obras pré-selecionadas, sem ao menos consultar a comunidade, não se caracterizam como política para a biblioteca.

Atividades bibliotecárias, quando realizadas por profissionais especializados e comprometidos, conduzem para o seu bom desempenho, principalmente porque afetam o indivíduo e o coletivo, ao possibilitar novas visões e perspectivas pessoais.

A partir da experiência, in loco, enquanto agente do quadro de implantação de biblioteca pública no Estado da Bahia, mesmo superando dificuldades e desafios, foi percebido o muito que ainda há por fazer.

Visando construir uma efetiva política em prol das bibliotecas públicas baianas, dentre outras considerações, um dos pontos a ser mais bem trabalhados, ou imprescindíveis, está na fiscalização contínua, apoio técnico e operacional por parte do Sistema Estadual de Bibliotecas Públicas; na articulação de parcerias com empresas e 
instituições do setor privado e organizações civis; no planejamento de ações culturais com ênfase na realidade de cada cidade; na atualização permanente do banco de dados dos relatórios estatísticos de uso e serviços da biblioteca; numa melhor articulação do sistema estadual com o nacional; em estabelecer campanha de mobilização junto aos prefeitos, antes de implantar biblioteca, a fim de despertar os benéficos que a mesma é capaz de trazer para a região. Assim busca-se sensibilizá-los quanto a relevância de dispor de orçamento público anual para manter ações básicas, chamar sua atenção para a importância de obter e manter sede própria para a biblioteca, além de abertura de concurso público para contratação de bibliotecário, do contrário caberia punir os transgressores que não honrarem com o pré-firmado em contrato com a FBN.

Os desafios históricos, moldados por uma cultura que não vê a biblioteca enquanto instrumento para o desenvolvimento humano, social e econômico, dificultam viabilizar e concluir políticas para as mesmas. Contudo, tais barreiras não impedem que por via de políticas específicas para biblioteca pública, formuladas com o apoio das autoridades governamentais e com o apoio da sociedade, busquemos soluções e propostas para combater e mudar o exposto. Caso contrário, a velha prática de abrir e fechar biblioteca nunca cessará.

\title{
Considerations of experience deploying municipal public libraries in the State of Bahia
}

\begin{abstract}
The article describes the process of deploying municipal public libraries in the State of Bahia, during the Lula government. Emphasizes the importance of cultural facilities and the relevance of specific policies to support them directly. The methodological procedure applied was bibliographic and documentary research, exploratory, conducted from a qualitative approach in order to seek clarification practices, collaborate and propose interventions. Concludes that existing policies for municipal public libraries are contradictory, when in fact they are essentially subordinate to the political books, fulfilling only a supporting role, leading sometimes to ignorance of its primary functions.
\end{abstract}

Keywords: Public Library - Public Policies. - State Library System - Bahia. 


\section{REFERÊNCIAS}

ALMEIDA, Ludmila; BASTOS, Gustavo Grandini; ROMÃO, Lucília Maria Sousa. Zerar o número de municípios brasileiros sem biblioteca": análise do discurso do Presidente Lula. Enc. Bibli: R. Eletr. Bibliotecon. Ci. Inf., Florianópolis, n. 26, $2^{\circ} \mathrm{sem}$, p. 229-242, 2008. Disponível em: <https://periodicos.ufsc.br/index.php/eb/article/view/1518-

2924.2008v13n26p229/6649>. Acesso em: 14 out. 2014.

BAHIA. Governo do Estado. Secretaria de Cultura. Fundação Pedro Calmon. Anuário Estatístico: das Bibliotecas Públicas do Estado da Bahia. Salvador: FPC, 2010.

BIBLIOTECA NACIONAL. Biblioteca Pública: princípios e diretrizes. Rio de Janeiro: Fundação Biblioteca Nacional, 2000.

BRITO, Julia de. Estado inaugura Biblioteca-Parque Estadual no Centro do Rio. Rio poupa tempo na web. Rio de Janeiro, 29 mar. 2014. Disponível em: <http://www.rj.gov.br/web/seobras/exibeconteudo?article-id=2015333>. Acesso em: 12 ago. 2014.

CASTRILlÓN, Silvia. O direito de ler e de escrever. São Paulo: Pulo do Gato, 2011.

COMUNIDADE BIBLIOTECA VIVA. Experiências de incentivo à leitura, apoiadas pelo Programa Mais Cultura estão na Bienal de São Paulo. Disponível em: <http://blogs.cultura.gov.br/bibliotecaviva/author/robson/>. Acesso em: 12 ago. 2014.

CUNHA JÚNIOR, Moaci Vilarino da; CORREIA Anna Elizabeth Galvão Coutinho. Abrindo e fechando portas: Diagnóstico das Bibliotecas Públicas Municipais da Região Metropolitana Norte de Recife - PE. Biblionline, João Pessoa, v. 3, n. 1, 2007.

FUNDAÇÃO BIBLIOTECA NACIONAL. A biblioteca pública: administração, organização, serviços. Rio de Janeiro: Departamento Nacional do Livro, 1995.

FUNDAÇÃO BIBLIOTECA NACIONAL. Programa Livro aberto: implantação de bibliotecas públicas. Informações básicas. Rio de Janeiro: FBN, 2007.

INTERNATIONAL FEDERATION OF LIBRARY ASSOCIATIONS AND INSTITUTIONS, The Hague; UNESCO, Paris. Manifesto da IFLA/UNESCO sobre bibliotecas públicas. $1994 . \quad$ Disponível em: <http://www.ifla.org/VII/s8/unesco/port.htm> Acesso em: 10 jun. 2011.

MEDEIROS, Ana Ligia Silva. Biblioteca e cidadania. Sinais sociais. Rio de Janeiro, v. 4, n. 13, p.10-45 maio/ago. 2010. 
MILANESI, Luís. A casa da invenção: biblioteca centro de cultura. São Paulo: Ateliê Editorial. 1997.

OLIVEIRA, Zita Catarina Prates. A biblioteca fora do tempo: políticas governamentais de bibliotecas públicas no Brasil, 1937-1989. 1994.Tese (Doutorado em Comunicação) - Universidade de São Paulo, São Paulo, 1994.

PAIVA, Marília de Abreu Martins de. Bibliotecas públicas: políticas do Estado brasileiro de 1990 a 2006. 2008, 140 f. Dissertação (Mestrado) - Universidade Federal de Minas Gerais, Escola de Ciência da Informação. Orientadora: Maria Eugênia Albino Andrade, 2008.

RANGANATHAN, S. R. As cinco leis da biblioteconomia. Tradução de Tarcisio Zandonade. Brasília: Briquet de Lemos, 2009.

ROSA, Juliana Vianna. Sistema Estadual de Biblioteca Pública no Rio Grande do Sul In: JORNADA SUL-RIO-GRANDENSE DE BIBLIOTECONOMIA E DOCUMENTAÇÃO, 7., 1982, Porto Alegre. Anais... Porto Alegre, Associação RioGrandense de Bibliotecários, 1982. p. 141-154.

SUAIDEN, Emir José. Biblioteca Pública Brasileira: desempenho e perspectivas. São Paulo: Lisa, 1980.

\section{Informações da autora}

Jovenilda Freitas dos Santos

Mestre em Ciência da Informação pelo PPGCI/UFBA

E-mail: jovfres@ig.com.br

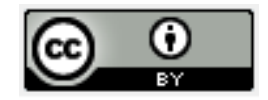

Recebido em 27.10.2014 e aceito para publicação em 15.07.2016 